\title{
Micromechanical Modeling Tensile and Fatigue Behavior of Fiber-Reinforced Ceramic-Matrix Composites Considering Matrix Fragmentation and Closure
}

\author{
Longbiao Li
}

Citation: Li, L. Micromechanical Modeling Tensile and Fatigue Behavior of Fiber-Reinforced Ceramic-Matrix Composites Considering Matrix Fragmentation and Closure. J. Compos. Sci. 2021, 5, 187. https://doi.org/10.3390/ jcs5070187

Academic Editor: Gérard L. Vignoles

Received: 12 June 2021

Accepted: 16 July 2021

Published: 16 July 2021

Publisher's Note: MDPI stays neutral with regard to jurisdictional claims in published maps and institutional affiliations.

Copyright: (C) 2021 by the author. Licensee MDPI, Basel, Switzerland. This article is an open access article distributed under the terms and conditions of the Creative Commons Attribution (CC BY) license (https:// creativecommons.org/licenses/by/ $4.0 /)$.
College of Civil Aviation, Nanjing University of Aeronautics and Astronautics, No.29 Jiangjun Ave., Nanjing 211106, China; 1lb451@nuaa.edu.cn

\begin{abstract}
In this paper, micromechanical constitutive models are developed to predict the tensile and fatigue behavior of fiber-reinforced ceramic-matrix composites (CMCs) considering matrix fragmentation and closure. Damage models of matrix fragmentation, interface debonding, and fiber's failure are considered in the micromechanical analysis of tensile response, and the matrix fragmentation closure, interface debonding and repeated sliding are considered in the hysteresis response. Relationships between the matrix fragmentation and closure, tensile and fatigue response, and interface debonding and fiber's failure are established. Experimental matrix fragmentation density, tensile curves, and fatigue hysteresis loops of mini, unidirectional, cross-ply, and 2D plain-woven $\mathrm{SiC} / \mathrm{SiC}$ composites are predicted using the developed constitutive models. Matrix fragmentation density changes with increasing or decreasing applied stress, which affects the nonlinear strain of $\mathrm{SiC} / \mathrm{SiC}$ composite under tensile loading, and the interface debonding and sliding range of $\mathrm{SiC} / \mathrm{SiC}$ composite under fatigue loading.
\end{abstract}

Keywords: ceramic-matrix composites (CMCs); micromechanics; tensile; fatigue; matrix fragmentation; matrix closure

\section{Introduction}

$\mathrm{SiC} / \mathrm{SiC}$ ceramic matrix composite (CMC) is a type of composite with the SiC fiber as reinforcement and $\mathrm{SiC}$ ceramic as matrix. It not only maintains the advantages of $\mathrm{SiC}$ ceramic, such as, high temperature resistance, high strength, low density, and oxidation resistance, but also possesses the toughening effect of the $\mathrm{SiC}$ fiber, and effectively overcomes the dangerous shortcoming of monolithic ceramics, such as, brittleness, sensitivity to defects or cracks and poor reliability. Compared with superalloy material, $\mathrm{SiC} / \mathrm{SiC}$ composites possess lower density (i.e., usually $2.0 \sim 3.0 \mathrm{~g} / \mathrm{cm}^{3}$, which is only $1 / 3 \sim 1 / 4$ of superalloy), and higher temperature resistance (i.e., the operating temperature with cooling is higher than $1200^{\circ} \mathrm{C}$ ). For the application in aeroengine, $\mathrm{SiC} / \mathrm{SiC}$ composites can reduce the structural weight, simplify cooling structure, reduce cooling air consumption, improve combustion efficiency, and increase thrust-weight-ratio. It is one of the most potential thermal structural materials for aeroengine hot-section components [1-4].

Under tensile and cyclic fatigue loading, multiple micro damage mechanisms occur and contribute to the nonlinear behavior of the composite [5-10]. With increasing applied tensile stress, matrix fragmentation occurs first, and the matrix fragmentation density increases to saturation. Sevener et al. [11] performed experimental investigation on crack opening behavior in 2D plain-woven melt infiltrated SiC/SiC composite under uniaxial tension using scanning electron microscopy (SEM) combined with digital image correlation (DIC) and manual crack opening displacement (COD) measurements. Crack openings were found to increase linearly with increasing applied stress. Li [12] developed a micromechanical model to predict the COD behavior of mini-SiC/SiC composite. Relationships between $\mathrm{COD}$, crack opening stress, interface debonding stress and interface debonding ratio were 
established. Chen et al. [13] investigated the crack initiation and propagation in braided $\mathrm{SiC} / \mathrm{SiC}$ tubes with different braiding angle using in situ tensile tests with synchrotron micro-computed tomography. The results show that braiding angle has no obvious effect on the location of crack onsets, whereas it significantly affects the paths of crack propagation. $\mathrm{Li}$ [14] predicted the first matrix fragmentation stress in fiber-reinforced CMCs using the energy balance approach considering fiber's debonding and fracture. Morscher et al. [15], Goulmy et al. [16] performed experimental investigations on matrix multiple cracking using the electrical resistance. Li [17] investigated multiple matrix fragmentation behavior of mini, unidirectional, and $2 \mathrm{D}$ plain-woven $\mathrm{SiC} / \mathrm{SiC}$ composites using critical matrix strain energy (CMSE) criterion. Matrix fragmentation density increased with the increasing of fiber's volume, fiber's elastic modulus, interface shear stress, and interface debonding energy, and the decreasing of the fiber's radius and matrix elastic modulus. Matrix fragmentation affects the tensile and fatigue behavior of fiber-reinforced CMCs [18-25]. Ahn and Curtin [26] investigated matrix stochastic fragmentation on hysteresis loops in unidirectional CMCs. Liu et al. [27] analyzed the hysteresis loops of 3D needle-punched $\mathrm{C} / \mathrm{SiC}$ composite and predicted the mechanical hysteresis loops for different tensile peak stress. The hysteresis-based damage parameters of inverse tangent modulus and interface debonding ratio were adopted to describe the composite's internal damage evolution. $\mathrm{Li}$ [28] predicted the non-closure hysteresis loops in fiber-reinforced CMCs at high tensile stress, due to the change of matrix fragmentation density with loading/unloading tensile stress. However, in the research mentioned above, the synergistic effect of matrix fragmentation and closure with increasing or decreasing tensile stress on tensile and fatigue behavior of fiber-reinforced CMCs have not been analyzed.

The objective of this paper is to develop a micromechanical constitutive model to analyze the effects of matrix fragmentation and closure on tensile and fatigue behavior of fiber-reinforced CMCs. Damage models of matrix fragmentation, interface debonding, and fiber's failure are considered in the micromechanical analysis for tensile response. Matrix fragmentation and closure, interface debonding and repeated sliding are considered in the micromechanical analysis for hysteresis response. Relationships between composite's tensile and fatigue response and matrix fragmentation and closure are established. Experimental tensile curves and fatigue hysteresis loops of mini, unidirectional, cross-ply, and 2D plain-woven $\mathrm{SiC} / \mathrm{SiC}$ composites are predicted.

\section{Micromechanical Constitutive Models}

Under tensile and cyclic loading/unloading tensile testing, matrix fragmentation with interface debonding occurs, and the fragmentation density increases with tensile peak stress. However, with decreasing applied stress, the matrix fragmentation density changes with applied stress, which would affect the mechanical hysteresis loops of fiberreinforced CMCs. In this section, the micromechanical constitutive models for monotonic tensile and cyclic loading/unloading hysteresis loops were developed considering matrix fragmentation and closure.

\subsection{Micromechanical Tensile Constitutive Model Considering Matrix Fragmentation}

For fiber-reinforced CMCs under tensile loading, damage mechanisms of matrix fragmentation, interface debonding and fiber's failure occur, and contribute to the nonlinear damage and fracture of composite's tensile response.

For the initial tensile loading, the composite's strain response is, [5]

$$
\varepsilon_{\mathrm{c}}=\frac{\sigma}{E_{\mathrm{c}}}
$$

where $\varepsilon_{\mathrm{c}}$ is the strain of composite, $\sigma$ is applied stress, and $E_{\mathrm{c}}$ is elastic modulus of composite. 
Considering damage mechanisms of matrix fragmentation, interface debonding and fiber's failure, the nonlinear composite's strain response is,

$$
\varepsilon_{\mathrm{c}}(\sigma)=\left\{\begin{array}{c}
\frac{\Phi}{E_{\mathrm{f}}} \eta-\frac{\tau_{\mathrm{i}}}{E_{\mathrm{f}}} \frac{l_{\mathrm{d}}}{r_{\mathrm{f}}} \eta+\frac{\sigma_{\mathrm{fo}}}{E_{\mathrm{f}}}(1-\eta)-\frac{1}{\rho E_{\mathrm{f}}} \frac{2 r_{\mathrm{f}}}{l_{\mathrm{c}}}\left(\Phi-\sigma_{\mathrm{fo}}-2 \frac{l_{\mathrm{d}}}{r_{\mathrm{f}}} \tau_{\mathrm{i}}\right) \\
\quad \times\left[\exp \left(-\frac{\rho}{2} \frac{l_{\mathrm{c}}}{r_{\mathrm{f}}}(1-\eta)\right)-1\right]-\left(\alpha_{\mathrm{c}}-\alpha_{\mathrm{f}}\right) \Delta \mathrm{T}, \eta<1 \\
\frac{\Phi}{E_{\mathrm{f}}}-\frac{\tau_{\mathrm{i}}}{E_{\mathrm{f}}} \frac{l_{\mathrm{c}}}{2 r_{\mathrm{f}}}-\left(\alpha_{\mathrm{c}}-\alpha_{\mathrm{f}}\right) \Delta \mathrm{T}, \eta=1
\end{array}\right.
$$

where $E_{\mathrm{f}}$ is the fiber's elastic modulus, $\Phi$ represents the intact fiber stress, $\tau_{\mathrm{i}}$ represents the shear stress at the interface, and $r_{\mathrm{f}}$ represents the fiber's radius; $l_{\mathrm{d}}$ and $l_{\mathrm{c}}$ are the lengths of the debonding and the space between the cracks in the matrix, respectively; $\eta$ is the ratio between $l_{\mathrm{d}}$ and half of $l_{\mathrm{c}} ; \sigma_{\mathrm{fo}}$ represents the fiber's axial stress levels in the interface bonding region; $\rho$ represents a shear-lag model parameter; $\alpha_{\mathrm{f}}$ and $\alpha_{\mathrm{c}}$ represent the coefficients of axial thermal expansion of the fiber and composite, respectively; $\Delta \mathrm{T}$ is the temperature difference between the test and fabrication temperatures. Curtin [29] developed a stochastic model to analysis matrix stochastic cracking inside CMCs, and the relationship between matrix crack spacing and applied stress can be determined by Equation (3). Gao et al. [30] developed a fracture mechanical approach to determine the interface debonding length when matrix crack propagates to the interface, and the relationship between the interface debonding length and the applied stress can be determined by Equation (4). The Global Load Sharing (GLS) criterion is adopted to determine the stress distribution between the intact and breakage fibers, which is given by Equation (5) [31].

$$
\begin{gathered}
l_{\mathrm{c}}=l_{\mathrm{sat}}\left\{1-\exp \left[-\left(\frac{\sigma_{\mathrm{m}}}{\sigma_{\mathrm{R}}}\right)^{m}\right]\right\}^{-1} \\
l_{\mathrm{d}}=\frac{r_{\mathrm{f}}}{2}\left(\frac{V_{\mathrm{m}} E_{\mathrm{m}}}{E_{\mathrm{c}} \tau_{i}} \Phi-\frac{1}{\rho}\right)-\sqrt{\left(\frac{r_{\mathrm{f}}}{2 \rho}\right)^{2}-\frac{r_{\mathrm{f}}^{2} V_{\mathrm{f}} V_{\mathrm{m}} E_{\mathrm{f}} E_{\mathrm{m}} \Phi}{4 E_{\mathrm{c}}^{2} \tau_{\mathrm{i}}^{2}}\left(\Phi-\frac{\sigma}{V_{\mathrm{f}}}\right)+\frac{r_{\mathrm{f}} V_{\mathrm{m}} E_{\mathrm{m}} E_{\mathrm{f}}}{E_{\mathrm{c}} \tau_{\mathrm{i}}^{2}} \Gamma_{\mathrm{i}}} \\
\frac{\sigma}{V_{\mathrm{f}}}=\Phi(1-P)+\frac{2 \tau_{\mathrm{i}}}{r_{\mathrm{f}}}\langle L\rangle P
\end{gathered}
$$

where $V_{\mathrm{f}}$ and $V_{\mathrm{m}}$ are the volume fraction of the fiber and the matrix, respectively; $E_{\mathrm{m}}$ is the elastic modulus of the matrix; $l_{\mathrm{sat}}$ is the saturation length of matrix cracking; $\sigma_{\mathrm{m}}$ represents the stress loaded on the matrix; $\sigma_{\mathrm{R}}$ represents the characteristic stress for cracks in the matrix; $\Gamma_{\mathrm{i}}$ represents the debonding energy at the interface; $\langle L\rangle$ corresponds to mean fiber pullout length, and $P$ represents the probability of fiber fragmentation.

\subsection{Micromechanical Cyclic Hysteresis Loops Constitutive Model Considering Matrix Fragmentation and Closure}

Upon unloading, the composite's strain is divided into two stages, as following:

- Stage I, when $\sigma_{\text {unloading }}>\sigma_{\text {tr_unloading, the unloading interface reverse slip length is }}$ less than the interface debonding length.

- Stage II, when $\sigma_{\min }<\sigma_{\text {unloading }}<\sigma_{\text {tr_unloading, }}$ the unloading interface reverse slip length is equal to the interface debonding length.

Upon unloading, when $\sigma_{\text {unloading }}>\sigma_{\text {tr_unloading, }}$ the composite's strain can be determined by Equation (6), [28]

$$
\begin{aligned}
\varepsilon_{\text {unloading }} & =\frac{\sigma_{\text {unloading }}}{V_{\mathrm{f}} E_{\mathrm{f}}} \eta+2 \frac{\tau_{\mathrm{i}}}{E_{\mathrm{f}}} \frac{l_{\mathrm{d}}}{r_{\mathrm{f}}} \eta \gamma^{2}-\frac{\tau_{\mathrm{i}}}{E_{\mathrm{f}}} \frac{l_{\mathrm{d}}}{\underline{\mathrm{f}}_{\mathrm{f}}} \eta(2 \gamma-1)^{2}+\frac{\sigma_{\mathrm{fo}}}{E_{\mathrm{f}}}(1-\eta) \\
& +\frac{1}{\rho E_{\mathrm{f}}}\left[2 \sigma_{\mathrm{mo}} \frac{V_{\mathrm{m}}}{V_{\mathrm{f}}} \frac{r_{\mathrm{f}}}{l_{\mathrm{c}}}-2 \tau_{\mathrm{i}} \eta(1-2 \gamma)\right]\left[1-\exp \left(-\frac{\rho l_{\mathrm{c}}}{2 r_{\mathrm{f}}}(1-\eta)\right)\right]-\left(\alpha_{\mathrm{c}}-\alpha_{\mathrm{f}}\right) \Delta \mathrm{T}
\end{aligned}
$$

where

$$
\eta=2 \frac{l_{\mathrm{d}}}{l_{\mathrm{c}}}, \gamma=\frac{l_{\text {counter_slip }}}{l_{\mathrm{d}}}
$$


When $\sigma_{\min }<\sigma_{\text {unloading }}<\sigma_{\text {tr_unloading, }}$ the composite's strain can be determined by Equation (8), [28]

$$
\begin{aligned}
\varepsilon_{\text {unloading }} & =\frac{\sigma_{\text {unloading }}}{V_{\mathrm{f}} E_{\mathrm{f}}} \eta+2 \frac{\tau_{\mathrm{i}}}{E_{\mathrm{f}}} \frac{l_{\mathrm{d}}}{r_{\mathrm{f}}} \eta-\frac{\tau_{\mathrm{i}}}{E_{\mathrm{f}}} \frac{l_{\mathrm{d}}}{r_{\mathrm{f}}} \eta+\frac{\sigma_{\mathrm{fo}}}{E_{\mathrm{f}}}(1-\eta) \\
& +\frac{1}{\rho E_{\mathrm{f}}}\left[2 \sigma_{\mathrm{mo}} \frac{V_{\mathrm{m}}}{V_{\mathrm{f}}} \frac{r_{\mathrm{f}}}{l_{\mathrm{c}}}+2 \tau_{\mathrm{i}} \eta\right]\left[1-\exp \left(-\frac{\rho l_{\mathrm{c}}}{2 r_{\mathrm{f}}}(1-\eta)\right)\right]-\left(\alpha_{\mathrm{c}}-\alpha_{\mathrm{f}}\right) \Delta \mathrm{T}
\end{aligned}
$$

Upon reloading, the composite's strain is divided into two stages, as following:

- Stage I, when $\sigma_{\text {reloading }}>\sigma>\sigma_{\min }$, the reloading interface new slip length is less than the interface debonding length.

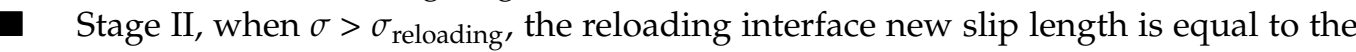
interface debonding length.

Upon reloading, when $\sigma_{\text {reloading }}>\sigma>\sigma_{\min }$, the composite's strain can be determined by Equation (9), [28]

$$
\begin{aligned}
\varepsilon_{\text {reloading }} & =\frac{\sigma}{V_{\mathrm{f}} E_{\mathrm{f}}} \eta-2 \frac{\tau_{\mathrm{i}}}{E_{\mathrm{f}}} \frac{l_{\mathrm{d}}}{r_{\mathrm{f}}} \eta \varphi^{2}+2 \frac{\tau_{\mathrm{i}}}{E_{\mathrm{f}}} \frac{l_{\mathrm{d}}}{r_{\mathrm{f}}} \eta(1-2 \varphi)^{2} \\
& -\frac{\tau_{\mathrm{i}}}{E_{\mathrm{f}}} \frac{l_{\mathrm{d}}}{r_{\mathrm{f}}} \eta(1-2 \varphi)^{2}+\frac{\sigma_{\mathrm{fo}}}{E_{\mathrm{f}}}(1-\eta) \\
& +\frac{2}{\rho E_{\mathrm{f}}}\left[\sigma_{\mathrm{mo}} \frac{V_{\mathrm{m}}}{V_{\mathrm{f}}} \frac{r_{\mathrm{f}}}{l_{\mathrm{c}}}-\tau_{\mathrm{i}} \eta(1-2 \eta+2 \varphi)\right]\left[1-\exp \left(-\frac{\rho}{2} \frac{l_{\mathrm{c}}}{r_{\mathrm{f}}}(1-\eta)\right)\right] \\
& -\left(\alpha_{\mathrm{c}}-\alpha_{\mathrm{f}}\right) \Delta \mathrm{T}
\end{aligned}
$$

where

$$
\varphi=\frac{l_{\text {new_slip }}}{l_{\mathrm{d}}}
$$

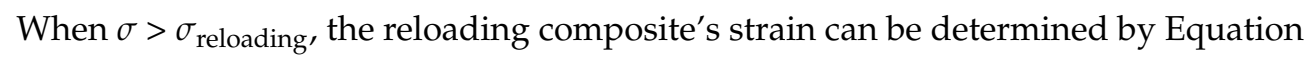
(11), [28]

$$
\begin{aligned}
\varepsilon_{\text {reloading }} & \left.=\frac{\sigma}{V_{\mathrm{f}} E_{\mathrm{f}}} \eta-2 \frac{\tau_{\mathrm{i}}}{E_{\mathrm{f}}} \frac{l_{\mathrm{d}}}{r_{\mathrm{f}}} \eta+2 \frac{\tau_{\mathrm{i}}}{E_{\mathrm{f}}} \frac{l_{\mathrm{d}}}{r_{\mathrm{f}}} \eta-\frac{\tau_{\mathrm{i}}}{E_{\mathrm{f}}} \frac{l_{\mathrm{d}}}{r_{\mathrm{f}}} \eta+\frac{\sigma_{\mathrm{fo}}}{E_{\mathrm{f}}}(1-\eta)\right] \\
& +\frac{2}{\rho E_{\mathrm{f}}}\left[\sigma_{\mathrm{mo}} \frac{V_{\mathrm{m}}}{V_{\mathrm{f}}} \frac{r_{\mathrm{f}}}{l_{\mathrm{c}}}-\tau_{\mathrm{i}} \eta(3-2 \eta)\right]\left[1-\exp \left(-\frac{\rho}{2} \frac{l_{\mathrm{c}}}{r_{\mathrm{f}}}(1-\eta)\right)\right] \\
& -\left(\alpha_{\mathrm{c}}-\alpha_{\mathrm{f}}\right) \Delta \mathrm{T}
\end{aligned}
$$

\section{Experimental Comparisons}

Experimental monotonic tensile, cyclic loading/unloading hysteresis loops, inverse tangent modulus (ITM), and interface counter slip ratio (ICSR)/interface new slip ratio (INSR) of mini, unidirectional, cross-ply, and 2D plain-woven $\mathrm{SiC} / \mathrm{SiC}$ composites are predicted using the developed models. Material properties of $\mathrm{SiC} / \mathrm{SiC}$ composites are listed in Table 1.

Table 1. Material properties of mini, unidirectional, cross-ply and 2D plain-woven SiC/SiC composites.

\begin{tabular}{ccccc}
\hline Items & Mini & Unidirectional & Cross-Ply & PD \\
\hline$V_{\mathrm{f}}$ & $0.43[32]$ & $0.25[33]$ & $0.25[34]$ & $0.36[35]$ \\
\hline$r_{\mathrm{f}} /(\mu \mathrm{m})$ & $3.5[32]$ & $7.5[34]$ & $7.5[34]$ & $7.5[35]$ \\
\hline$E_{\mathrm{f}} /(\mathrm{GPa})$ & $387[35]$ & $420[34]$ & $420[34]$ & $350[35]$ \\
\hline$E_{\mathrm{m}} /(\mathrm{GPa})$ & $400[35]$ & $339[34]$ & $339[34]$ & $400[35]$ \\
\hline$\alpha_{\mathrm{f}} /\left(10^{-6} / \mathrm{K}\right)$ & $2.3[34]$ & $5.1[34]$ & $5.1[34]$ & $4[29]$ \\
\hline$\alpha_{\mathrm{m}} /\left(10^{-6} / \mathrm{K}\right)$ & $1.48[34]$ & $4.38[34]$ & $4.38[34]$ & $4.6[29]$ \\
\hline$\Delta \mathrm{T} /\left({ }^{\circ} \mathrm{C}\right)$ & $-1000[32]$ & $-1400[34]$ & $-1400[34]$ & $-1400[35]$ \\
\hline$\tau_{\mathrm{i}} /(\mathrm{MPa})$ & $100[33]$ & $60[34]$ & $30[34]$ & $100[33]$ \\
\hline$\Gamma_{\mathrm{I}} /\left(\mathrm{J} / \mathrm{m}^{2}\right)$ & $4.0[33]$ & $5[29]$ & $2.0[33]$ & $6.0[33]$ \\
\hline
\end{tabular}




\subsection{Prediction of Tensile and Fatigue Hysteresis Loops of Mini-SiC/SiC Composite}

Sauder et al. [33] performed experimental study on the tensile and cyclic loading/unloading fatigue hysteresis behavior of mini-SiC/SiC composite. The mini-SiC/SiC composite was fabricated using the chemical vapor infiltration (CVI) method. Tyranno ${ }^{\mathrm{TM}}$ SA3 (UBE Industries, Tokyo, Japan) tows coated by a single layer of pyrocarbon (PyC) were used as reinforcement.

Figure 1 shows the experimental and predicted tensile stress-strain curves and matrix fragmentation density versus applied stress curves. Matrix fragmentation starts from approximately $\sigma_{\mathrm{mc}}=600 \mathrm{MPa}$, and approaches saturation at approximately $\sigma_{\text {sat }}=1000 \mathrm{MPa}$, and the saturation fragmentation density is approximately $\lambda_{\text {sat }}=25 / \mathrm{mm}$. During tensile experiment, acoustic emission was used to monitor the matrix crack evolution, and after the fracture of tensile specimen, the saturation matrix cracking density was obtained [33]. The occurrence of matrix fragmentation causes nonlinear behavior of tensile curve, and the composite tensile strength is approximately $\sigma_{\mathrm{UTS}}=1116 \mathrm{MPa}$ with the fracture strain $\varepsilon_{\mathrm{f}}=0.58 \%$.
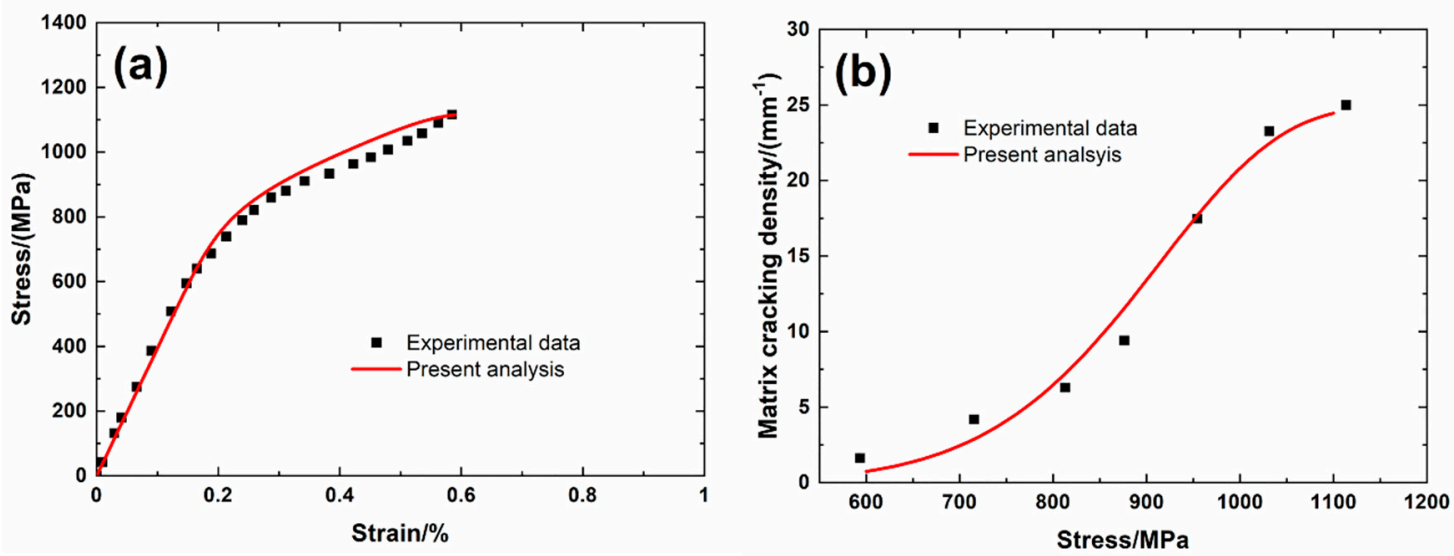

Figure 1. (a) Experimental and predicted tensile curves; and (b) matrix fragmentation density versus applied stress curves of mini-SiC/SiC composite.

Figure 2 shows the experimental and predicted cyclic loading/unloading hysteresis loops, ITM, and ICSR/INSR of mini-SiC/SiC composite without/with considering matrix fragmentation closure under $\sigma_{\max }=935 \mathrm{MPa}$. Theoretical predicted hysteresis loops considering closure of matrix fragmentation agreed with experimental data, as shown in Figure 2a.

(a) Under $\sigma_{\max }=935 \mathrm{MPa}$, when the closure of matrix fragmentation is not considered, the unloading ITM increases with unloading stress due to internal damage of interface debonding and counter sliding, i.e., from ITM $=3.1 \mathrm{TPa}^{-1}$ at the tensile peak stress $\sigma_{\max }=935 \mathrm{MPa}$ to ITM $=3.48 \mathrm{TPa}^{-1}$ at the unloading transition stress $\sigma_{\text {tr_unloading }}$ $=427 \mathrm{MPa}$ (i.e., $\mathrm{A}-\mathrm{B}_{1}$ in Figure $2 \mathrm{~b}$ ), and then increases to ITM $=3.73 \mathrm{TPa}^{-1}$ at the valley stress $\sigma_{\min }=$ zero $\mathrm{MPa}$ (i.e., $\mathrm{B}_{1}-\mathrm{C}_{1}$ in Figure $2 \mathrm{~b}$ ); the reloading ITM increases with reloading stress due to internal damage of interface debonding and new sliding, i.e., from ITM $=3.1 \mathrm{TPa}^{-1}$ at the valley stress $\sigma_{\min }=$ zero MPa to ITM $=3.48 \mathrm{TPa}^{-1}$ at the reloading transition stress $\sigma_{\text {tr_reloading }}=508 \mathrm{MPa}$ (i.e., $\mathrm{A}-\mathrm{B}_{1}$ in Figure $2 \mathrm{c}$ ), and increases to ITM $=3.73 \mathrm{TPa}^{-1}$ at the tensile peak stress $\sigma_{\max }=935 \mathrm{MPa}$ (i.e., $\mathrm{B}_{1}-\mathrm{C}_{1}$ in Figure 2c); the unloading ICSR increases with unloading stress due to the increase of interface counter slip length, i.e., from ICSR $=$ zero at the tensile peak stress $\sigma_{\max }$ $=935 \mathrm{MPa}$ to ICSR $=0.194$ at the unloading transition stress $\sigma_{\text {tr_unloading }}=427 \mathrm{MPa}$ (i.e., $\mathrm{A}-\mathrm{B}_{1}$ in Figure $2 \mathrm{~d}$ ), and remains constant till the unloading valley stress $\sigma_{\min }=$ zero $\mathrm{MPa}$ (i.e., $\mathrm{B}_{1}-\mathrm{C}_{1}$ in Figure $2 \mathrm{~d}$ ); and the reloading INSR increases with reloading stress due to the increase of the interface new slip length, i.e., from INSR = zero at 
the valley stress $\sigma_{\min }=$ zero MPa to INSR $=0.194$ at the reloading transition stress $\sigma_{\text {tr_reloading }}=508 \mathrm{MPa}$ (i.e., $\mathrm{A}-\mathrm{B}_{2}$ in Figure 2e), and then remains constant till the tensile peak stress $\sigma_{\max }=935 \mathrm{MPa}$ (i.e., $\mathrm{B}_{2}-\mathrm{C}$ in Figure 2e).

(b) Considering the closure of matrix fragmentation, the unloading ITM increases with unloading stress due to internal damage of interface debonding and counter sliding, i.e., from ITM $=3.1 \mathrm{TPa}^{-1}$ at the tensile peak stress $\sigma_{\max }=935 \mathrm{MPa}$ to ITM $=4.15 \mathrm{TPa}^{-1}$ at the unloading stress $\sigma_{\text {unloading }}=229 \mathrm{MPa}$ (i.e., $\mathrm{A}-\mathrm{B}_{2}$ in Figure $2 \mathrm{~b}$ ), and then decreases to ITM $=3.97 \mathrm{TPa}^{-1}$ at the valley stress $\sigma_{\min }=$ zero $\mathrm{MPa}$ (i.e., $\mathrm{B}_{2}-\mathrm{C}_{2}$ in Figure $2 \mathrm{~b}$ ); the reloading ITM increases with reloading stress due to internal damage of interface debonding and new sliding, i.e., from ITM $=3.1 \mathrm{TPa}^{-1}$ at the valley stress $\sigma_{\text {min }}=$ zero $\mathrm{MPa}$ to ITM $=3.9 \mathrm{TPa}^{-1}$ at the reloading stress $\sigma_{\text {reloading }}=508 \mathrm{MPa}$ (i.e., $\mathrm{A}-\mathrm{B}_{2}$ in Figure 2c), and increases slowly to ITM $=3.97 \mathrm{TPa}^{-1}$ at the tensile peak stress $\sigma_{\text {max }}$ $=935 \mathrm{MPa}$ (i.e., $\mathrm{B}_{2}-\mathrm{C}$ in Figure $2 \mathrm{c}$ ); the unloading ICSR increases with unloading stress due to the increase of interface counter slip length, i.e., from ICSR = zero at the tensile peak stress $\sigma_{\max }=935 \mathrm{MPa}$ to ICSR $=0.143$ at the unloading stress $\sigma_{\text {unloading }}=$ $486 \mathrm{MPa}$ (i.e., $\mathrm{A}-\mathrm{B}_{2}$ in Figure $2 \mathrm{~d}$ ), and decreases to ICSR = zero the valley stress $\sigma_{\min }$ $=$ zero $\mathrm{MPa}$ (i.e., $\mathrm{B}_{2}-\mathrm{C}_{2}$ in Figure $2 \mathrm{~d}$ ); and the reloading INSR increases with reloading stress due to the increase of the interface new slip length, i.e., from INSR = zero at the valley stress $\sigma_{\min }=$ zero $\mathrm{MPa}$ to INSR $=0.194$ at the reloading stress $\sigma_{\text {reloading }}=$ $589 \mathrm{MPa}$ (i.e., $\mathrm{A}-\mathrm{B}_{2}$ in Figure $2 \mathrm{e}$ ), and then remains constant till the peak stress $\sigma_{\max }=$ $935 \mathrm{MPa}$ (i.e., $\mathrm{B}_{2}-\mathrm{C}$ in Figure 2e).
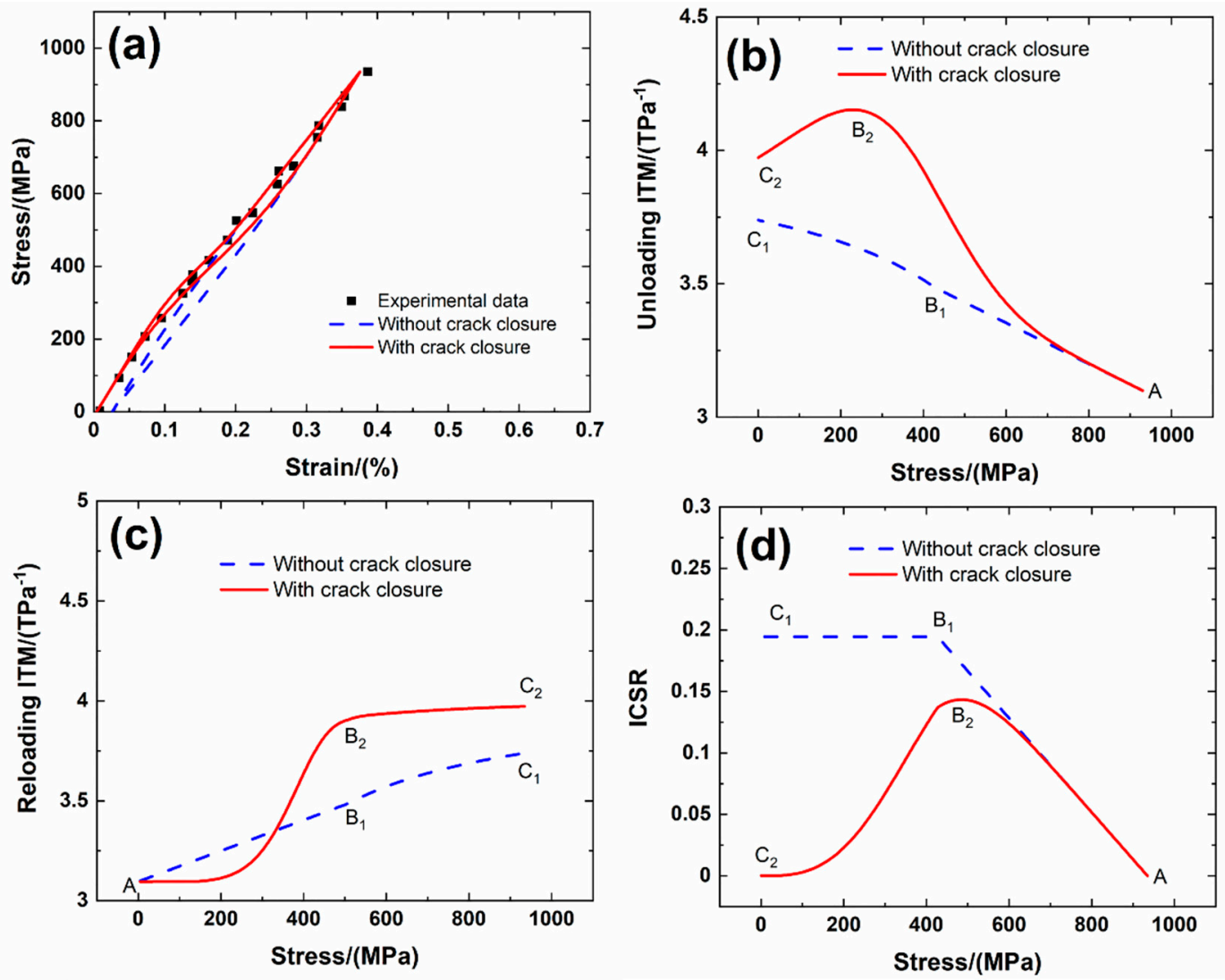

Figure 2. Cont. 


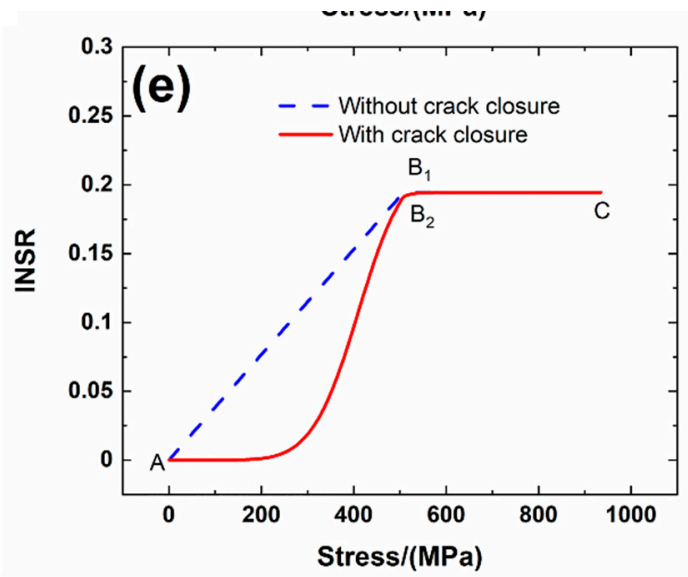

Figure 2. (a) Experimental and predicted loading/unloading hysteresis loops; (b) unloading ITM; (c) reloading ITM; (d) unloading ICSR; and (e) reloading INSR of mini-SiC $/ \mathrm{SiC}$ composite under $\sigma_{\max }=935 \mathrm{MPa}$.

Table 2 shows the hysteresis loops related parameters of mini-SiC/SiC composite under $\sigma_{\max }=890,935$, and $1078 \mathrm{MPa}$. When the tensile peak stress increases, the interface debonding ratio increases from $\eta=0.075$ at $\sigma_{\max }=890 \mathrm{MPa}$ to $\eta=0.38$ at $\sigma_{\max }=1078 \mathrm{MPa}$; the unloading transition stress decreases from $\sigma_{\text {tr_unloading }}=563 \mathrm{MPa}$ at $\sigma_{\max }=890 \mathrm{MPa}$ to $\sigma_{\text {tr_unloading }}=195 \mathrm{MPa}$ at $\sigma_{\max }=1078 \mathrm{MPa}$; the unloading peak ITM increases from ITM = 3.58 to $5.18 \mathrm{TPa}^{-1}$; the unloading peak ICSR increases from 0.07 at $\sigma_{\max }=890 \mathrm{MPa}$ to 0.17 at $\sigma_{\max }=1078 \mathrm{MPa}$; the reloading transition stress increases from $\sigma_{\text {tr_reloading }}=327 \mathrm{MPa}$ at $\sigma_{\max }=890 \mathrm{MPa}$ to $\sigma_{\text {tr_unloading }}=883 \mathrm{MPa}$ at $\sigma_{\max }=1078 \mathrm{MPa}$; the reloading ITM increases from ITM $=3.486$ to $4.87 \mathrm{TPa}^{-1}$; and the reloading peak INSR increases from 0.075 at $\sigma_{\max }$ $=890 \mathrm{MPa}$ to 0.38 at $\sigma_{\max }=1078 \mathrm{MPa}$.

Table 2. Hysteresis loops parameters of mini-SiC/SiC composite considering closure of matrix fragmentation.

\begin{tabular}{cccc}
\hline Items & $\sigma_{\max }=\mathbf{8 9 0} \mathbf{M P a}$ & $\sigma_{\text {max }}=\mathbf{9 3 5} \mathbf{M P a}$ & $\sigma_{\text {max }}=\mathbf{1 0 7 8} \mathbf{M P a}$ \\
\hline$\eta$ & 0.075 & 0.194 & 0.38 \\
\hline$\sigma_{\text {tr_unloading }} /(\mathrm{MPa})$ & 563 & 427 & 195 \\
\hline \begin{tabular}{c}
$\sigma_{\text {tr_reloading }} /(\mathrm{MPa})$ \\
\hline $\left.\begin{array}{c}\text { Unloading Peak } \\
\text { ITM/(TPa }\end{array}{ }^{-1}\right)$
\end{tabular} & 327 & 508 & 883 \\
\hline $\left.\begin{array}{c}\text { Reloading Peak } \\
\text { ITM/(TPa }\end{array}{ }^{-1}\right)$ & 3.58 & 4.15 & 5.18 \\
\hline Unloading Peak ICSR & 3.486 & 3.97 & 4.87 \\
\hline Reloading Peak INSR & 0.07 & 0.143 & 0.17 \\
\hline
\end{tabular}

\subsection{Prediction of Fatigue Hysteresis Loops of Unidirectional SiC/SiC Composite}

Gordon [34] performed experimental study on cyclic loading/unloading hysteresis behavior of unidirectional $\mathrm{SiC} / \mathrm{SiC}$ composite. The composite was fabricated using the pre-impregnated (pre-preg) melt-infiltrated (MI) method. The Hi-Nicalon Type $\mathrm{S}^{\mathrm{TM}}$ fibers were coated with a boron-nitride $(\mathrm{BN})$ interphase. Experimental and predicted tensile loading/unloading curves, ITM, and ICSR/INSR curves are shown in Figure 3. Theoretical predicted hysteresis loops considering closure of matrix fragmentation agreed with experimental data, as shown in Figure 3a. 

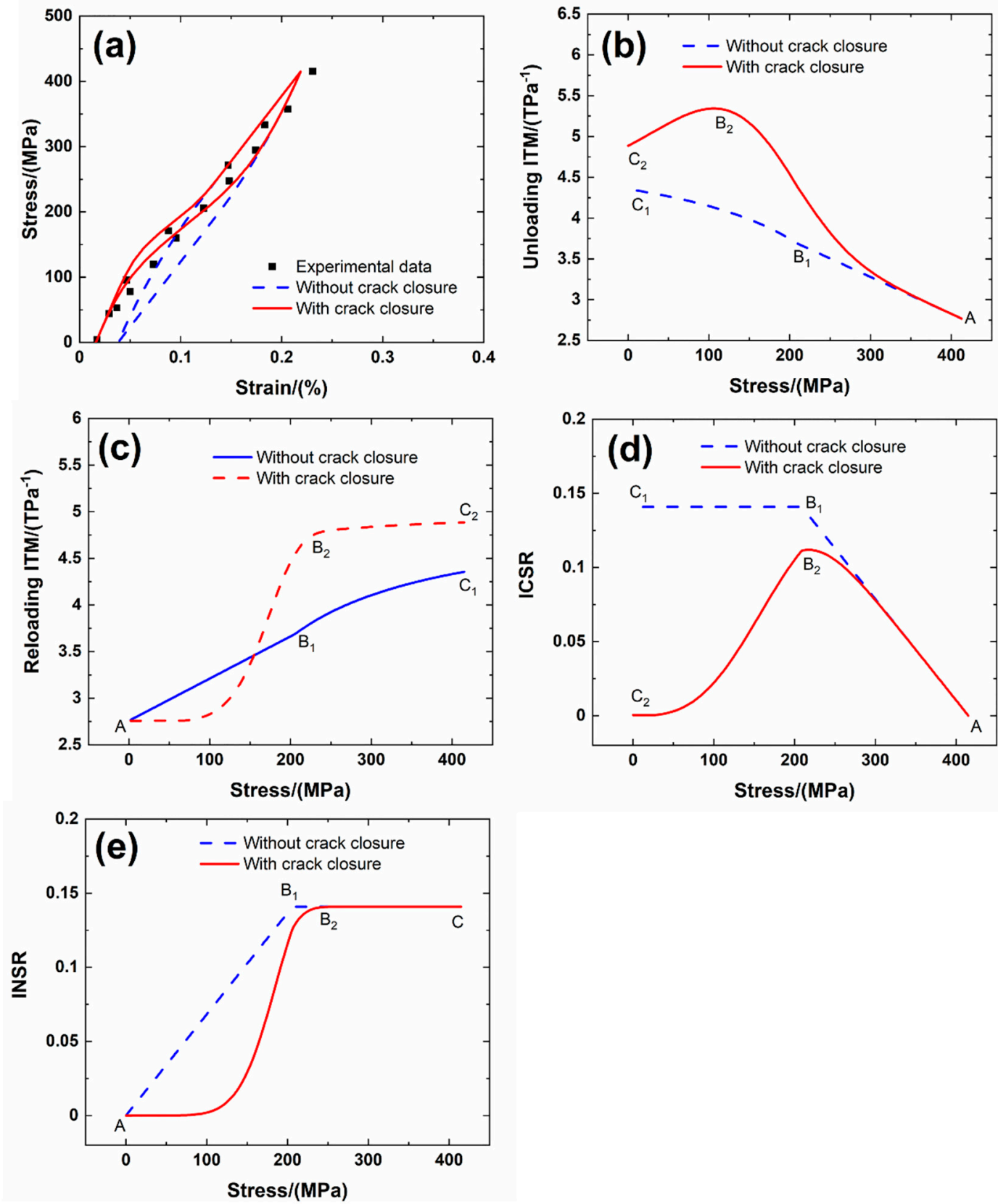

Figure 3. (a) Experimental and predicted hysteresis loops; (b) unloading ITM; (c) reloading ITM; (d) unloading ICSR; and (e) reloading INSR of unidirectional $\mathrm{SiC} / \mathrm{SiC}$ composite under $\sigma_{\max }=415 \mathrm{MPa}$.

(a) Under $\sigma_{\max }=415 \mathrm{MPa}$, when the closure of matrix fragmentation is not considered, the unloading ITM increases with unloading stress due to internal damage of interface debonding and counter sliding, i.e., from ITM $=2.76 \mathrm{TPa}^{-1}$ at the tensile peak stress $\sigma_{\max }=415 \mathrm{MPa}$ to ITM $=3.68 \mathrm{TPa}^{-1}$ at the unloading transition stress $\sigma_{\text {tr_unloading }}$ $=209 \mathrm{MPa}$ (i.e., $\mathrm{A}-\mathrm{B}_{1}$ in Figure $3 \mathrm{~b}$ ), and then increases to ITM $=4.35 \mathrm{TPa}^{-1}$ at the valley stress $\sigma_{\min }=$ zero $\mathrm{MPa}$ (i.e., $\mathrm{B}_{1}-\mathrm{C}_{1}$ in Figure $3 \mathrm{~b}$ ); the reloading ITM increases with reloading stress due to internal damage of interface debonding and new sliding, i.e., from ITM $=2.76 \mathrm{TPa}^{-1}$ at the valley stress $\sigma_{\min }=$ zero MPa to ITM $=3.68 \mathrm{TPa}^{-1}$ at the reloading transition stress $\sigma_{\text {tr_reloading }}=206 \mathrm{MPa}$ (i.e., $\mathrm{A}-\mathrm{B}_{1}$ in Figure $3 \mathrm{c}$ ), and increases to ITM $=4.35 \mathrm{TPa}^{-1}$ at the tensile peak stress $\sigma_{\max }=415 \mathrm{MPa}$ (i.e., $\mathrm{B}_{1}-\mathrm{C}_{1}$ in Figure 3c); the unloading ICSR increases with unloading stress due to the increase of interface counter slip length, i.e., from ICSR = zero at the tensile peak stress $\sigma_{\max }$ 
$=415 \mathrm{MPa}$ to ICSR $=0.14$ at the unloading transition stress $\sigma_{\text {tr_unloading }}=209 \mathrm{MPa}$ (i.e., $\mathrm{A}-\mathrm{B}_{1}$ in Figure $3 \mathrm{~d}$ ), and remains constant till the valley stress $\sigma_{\min }=$ zero $\mathrm{MPa}$ (i.e., $B_{1}-C_{1}$ in Figure $3 d$ ); and the reloading INSR increases with reloading stress due to the increase of the interface new slip length, i.e., from INSR = zero at the valley stress $\sigma_{\min }=$ zero $\mathrm{MPa}$ to INSR $=0.14$ at the reloading transition stress $\sigma_{\text {tr_reloading }}=$ $206 \mathrm{MPa}$ (i.e., $\mathrm{A}-\mathrm{B}_{1}$ in Figure $3 \mathrm{e}$ ), and then remains constant till the tensile peak stress $\sigma_{\max }=415 \mathrm{MPa}$ (i.e., $\mathrm{B}_{1}-\mathrm{C}$ in Figure $3 \mathrm{e}$ ).

(b) When the closure of matrix fragmentation is considered, the unloading ITM increases with unloading stress due to internal damage of interface debonding and counter sliding, i.e., from ITM $=2.76 \mathrm{TPa}^{-1}$ at the peak stress $\sigma_{\max }=415 \mathrm{MPa}$ to ITM $=5.34 \mathrm{TPa}^{-1}$ at the unloading stress $\sigma_{\text {unloading }}=105.8 \mathrm{MPa}$ (i.e., $\mathrm{A}-\mathrm{B}_{2}$ in Figure $3 \mathrm{~b}$ ), and then decreases to ITM $=4.88 \mathrm{TPa}^{-1}$ at the valley stress $\sigma_{\text {min }}=$ zero $\mathrm{MPa}$ (i.e., $\mathrm{B}_{2}-\mathrm{C}_{2}$ in Figure $3 b$ ); the reloading ITM increases with reloading stress due to internal damage of interface debonding and new sliding, i.e., from ITM $=2.75 \mathrm{TPa}^{-1}$ at the valley stress $\sigma_{\min }=$ zero $\mathrm{MPa}$ to ITM $=4.53 \mathrm{TPa}^{-1}$ at the reloading stress $\sigma_{\text {reloading }}=206 \mathrm{MPa}$ (i.e., $\mathrm{A}-\mathrm{B}_{2}$ in Figure $3 \mathrm{c}$ ), and increases slowly to ITM $=4.88 \mathrm{TPa}^{-1}$ at the tensile peak stress $\sigma_{\max }=415 \mathrm{MPa}$ (i.e., $\mathrm{B}_{2}-\mathrm{C}_{2}$ in Figure $3 \mathrm{c}$ ); the unloading ICSR increases with unloading stress due to the increase of the interface counter slip length, i.e., from $\mathrm{ICSR}=$ zero at the tensile peak stress $\sigma_{\max }=415 \mathrm{MPa}$ to ICSR $=0.11$ at the unloading stress $\sigma_{\text {unloading }}=217.8 \mathrm{MPa}$ (i.e., $\mathrm{A}-\mathrm{B}_{2}$ in Figure $3 \mathrm{~d}$ ), and decreases to $\mathrm{ICSR}=$ zero the valley stress $\sigma_{\min }=$ zero $\mathrm{MPa}$ (i.e., $\mathrm{B}_{2}-\mathrm{C}_{2}$ in Figure $3 \mathrm{~d}$ ); and the reloading INSR increases with reloading stress due to the increase of the interface new slip length, i.e., from INSR $=$ zero at the valley stress $\sigma_{\min }=$ zero MPa to INSR $=0.14$ at the reloading stress $\sigma_{\text {reloading }}=236 \mathrm{MPa}$ (i.e., $\mathrm{A}-\mathrm{B}_{2}$ in Figure $3 \mathrm{e}$ ), and then remains constant till the tensile peak stress $\sigma_{\max }=415 \mathrm{MPa}$ (i.e., $\mathrm{B}_{2}-\mathrm{C}$ in Figure $3 \mathrm{e}$ ).

Table 3 shows the hysteresis loops related parameters of unidirectional $\mathrm{SiC} / \mathrm{SiC}$ composite under $\sigma_{\max }=415$ and $449 \mathrm{MPa}$. When the peak stress increases from $\sigma_{\max }=415$ to $449 \mathrm{MPa}$, the interface debonding ratio increases from $\eta=0.14$ to 0.295 ; the unloading transition stress decreases from $\sigma_{\text {tr_unloading }}=209$ to $170 \mathrm{MPa}$; the unloading ITM increases from ITM = 5.34 to $7.21 \mathrm{TPa}^{-1}$; the unloading peak ICSR increases from 0.11 to 0.1888 ; the reloading transition stress increases from $\sigma_{\text {tr_reloading }}=206$ to $279 \mathrm{MPa}$; the reloading peak INSR increases from 0.14 to 0.295 ; and the reloading ITM increases from ITM $=4.88$ to 6.76 $\mathrm{TPa}^{-1}$.

Table 3. Hysteresis loops parameters of unidirectional SiC/SiC composite considering closure of matrix fragmentation.

\begin{tabular}{ccc}
\hline Items & $\sigma_{\max }=\mathbf{4 1 5} \mathbf{M P a}$ & $\sigma_{\max }=\mathbf{4 4 9} \mathbf{M P a}$ \\
\hline$\eta$ & 0.14 & 0.295 \\
\hline$\sigma_{\text {tr_unloading }} /(\mathrm{MPa})$ & 209 & 170 \\
\hline$\sigma_{\text {tr_reloading }} /(\mathrm{MPa})$ & 206 & 279 \\
\hline Unloading Peak ITM/(TPa $\left.{ }^{-1}\right)$ & 5.34 & 7.21 \\
\hline Reloading Peak ITM/(TPa $\left.{ }^{-1}\right)$ & 4.88 & 6.76 \\
\hline Unloading Peak ICSR & 0.11 & 0.188 \\
\hline Reloading Peak INSR & 0.14 & 0.295 \\
\hline
\end{tabular}

\subsection{Prediction of Fatigue Hysteresis Loops of Cross-Ply SiC/SiC Composite}

Gordon [34] performed experimental study on the cyclic loading/unloading hysteresis behavior of cross-ply [0/90 $]_{2 s} \mathrm{SiC} / \mathrm{SiC}$ composite. The composite was fabricated using the pre-impregnated (pre-preg) melt-infiltrated (MI) method. The Hi-Nicalon Type $S^{\mathrm{TM}}$ fibers were coated with a boron-nitride (BN) interphase. Experimental and predicted tensile loading/unloading hysteresis loops, ITM, and ICSR/INSR are shown in Figure 4. 
Theoretical predicted hysteresis loops considering closure of matrix fragmentation agreed with experimental data, as shown in Figure 4a.
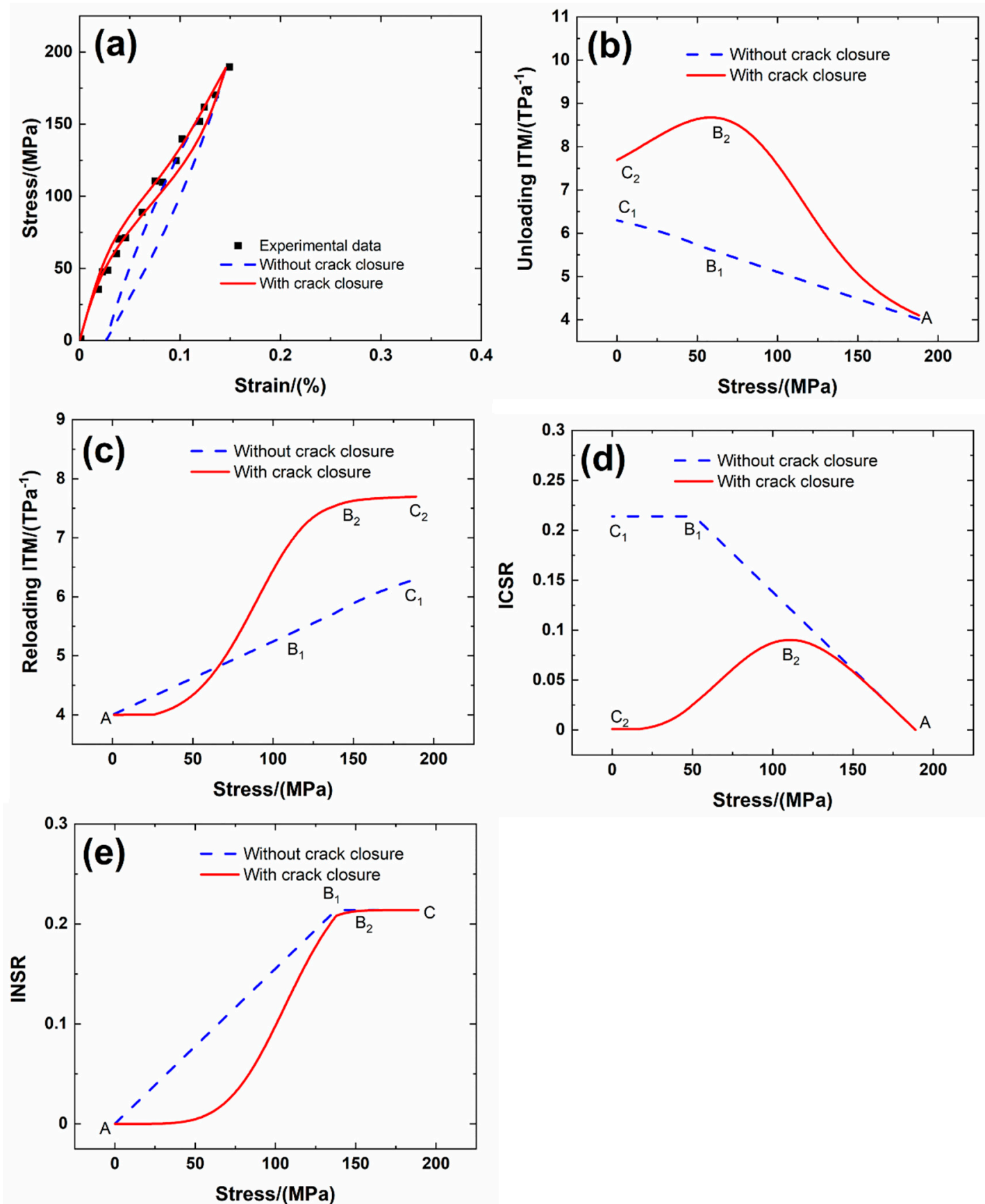

Figure 4. (a) Experimental and predicted hysteresis loops; (b) unloading ITM; (c) reloading ITM; (d) unloading ICSR; and (e) reloading INSR of unidirectional $\mathrm{SiC} / \mathrm{SiC}$ composite under $\sigma_{\max }=189 \mathrm{MPa}$.

(a) Under $\sigma_{\max }=189 \mathrm{MPa}$, when the closure of matrix fragmentation is not considered, the unloading ITM increases with unloading stress due to internal damage of interface debonding and counter sliding, i.e., from ITM $=4.01 \mathrm{TPa}^{-1}$ at the tensile peak stress $\sigma_{\max }=189 \mathrm{MPa}$ to ITM $=5.7 \mathrm{TPa}^{-1}$ at the transition stress $\sigma_{\text {tr_ unloading }}=52 \mathrm{MPa}$ (i.e., A- $B_{1}$ in Figure $4 \mathrm{~b}$ ), and then increases to ITM $=6.29 \mathrm{TPa}^{-1}$ at the valley stress $\sigma_{\text {min }}$ $=$ zero $\mathrm{MPa}$ (i.e., $\mathrm{B}_{1}-\mathrm{C}_{1}$ in Figure $4 \mathrm{~b}$ ); the reloading ITM increases with reloading stress due to internal damage of interface debonding and new sliding, i.e., from ITM $=4.01 \mathrm{TPa}^{-1}$ at the valley stress $\sigma_{\min }=$ zero $\mathrm{MPa}$ to ITM $=5.7 \mathrm{TPa}^{-1}$ at the reloading 
transition stress $\sigma_{\text {tr_reloading }}=137 \mathrm{MPa}$ (i.e., $\mathrm{A}-\mathrm{B}_{1}$ in Figure $4 \mathrm{c}$ ), and increases to ITM $=6.29 \mathrm{TPa}^{-1}$ at the tensile peak stress $\sigma_{\max }=189 \mathrm{MPa}$ (i.e., $\mathrm{B}_{1}-\mathrm{C}_{1}$ in Figure $4 \mathrm{c}$ ); the unloading ICSR increases with unloading stress due to the increase of the interface counter slip length, i.e., from ICSR = zero at the tensile peak stress $\sigma_{\max }=189 \mathrm{MPa}$ to $\mathrm{ICSR}=0.214$ at the unloading transition stress $\sigma_{\text {tr_unloading }}=52 \mathrm{MPa}$ (i.e., $\mathrm{A}-\mathrm{B}_{1}$ in Figure $4 \mathrm{~d}$ ), and remains constant till the valley stress $\sigma_{\min }=$ zero $\mathrm{MPa}$ (i.e., $\mathrm{B}_{1}-\mathrm{C}_{1}$ in Figure $4 \mathrm{~d}$ ); and the reloading INSR increases with reloading stress due to the increase of the interface new slip length, i.e., from INSR = zero at the valley stress $\sigma_{\min }=$ zero $\mathrm{MPa}$ to INSR $=0.214$ at the transition stress $\sigma_{\text {tr_reloading }}=137 \mathrm{MPa}$ (i.e., $\mathrm{A}-\mathrm{B}_{1}$ in Figure $4 \mathrm{e}$ ), and then remains constant till the peak stress $\sigma_{\max }=189 \mathrm{MPa}$ (i.e., $\mathrm{B}_{1}-\mathrm{C}$ in Figure 4e).

(b) When the closure of matrix fragmentation is considered, the unloading ITM increases with unloading stress due to internal damage of interface debonding and counter sliding, i.e., from ITM $=4.01 \mathrm{TPa}^{-1}$ at the tensile peak stress $\sigma_{\max }=189 \mathrm{MPa}$ to ITM $=$ 8.67 $\mathrm{TPa}^{-1}$ at the unloading stress $\sigma_{\text {unloading }}=58.6 \mathrm{MPa}$ (i.e., $\mathrm{A}-\mathrm{B}_{2}$ in Figure $4 \mathrm{~b}$ ), and then decreases to ITM $=7.69 \mathrm{TPa}^{-1}$ at the valley stress $\sigma_{\min }=$ zero $\mathrm{MPa}$ (i.e., $\mathrm{B}_{2}-\mathrm{C}_{2}$ in Figure $4 \mathrm{~b}$ ); the reloading ITM increases with reloading stress due to internal damage of interface debonding and new sliding, i.e., from ITM $=4 \mathrm{TPa}^{-1}$ at the valley stress $\sigma_{\text {min }}=$ zero $\mathrm{MPa}$ to ITM $=7.52 \mathrm{TPa}^{-1}$ at the reloading stress $\sigma_{\text {reloading }}=137 \mathrm{MPa}$ (i.e., $\mathrm{A}-\mathrm{B}_{2}$ in Figure $4 \mathrm{c}$ ), and increases slowly to ITM $=7.69 \mathrm{TPa}^{-1}$ at the tensile peak stress $\sigma_{\max }=189 \mathrm{MPa}$ (i.e., $\mathrm{B}_{2}-\mathrm{C}_{2}$ in Figure 4c); the unloading ICSR increases with unloading stress due to the increase of the interface counter slip length, i.e., from ICSR $=$ zero at the peak stress $\sigma_{\max }=189 \mathrm{MPa}$ to ICSR $=0.09$ at the unloading stress $\sigma_{\text {unloading }}=110 \mathrm{MPa}$ (i.e., $\mathrm{A}-\mathrm{B}_{2}$ in Figure $4 \mathrm{~d}$ ), and decreases to ICSR = zero the valley stress $\sigma_{\min }=$ zero $\mathrm{MPa}$ (i.e., $\mathrm{B}_{2}-\mathrm{C}_{2}$ in Figure $4 \mathrm{~d}$ ); and the reloading INSR increases with reloading stress due to the increase of the interface new slip length, i.e., from INSR $=$ zero at the valley stress $\sigma_{\min }=$ zero $\mathrm{MPa}$ to $\mathrm{INSR}=0.214$ at the reloading stress $\sigma_{\text {reloading }}=164 \mathrm{MPa}$ (i.e., $\mathrm{A}-\mathrm{B}_{2}$ in Figure $4 \mathrm{e}$ ), and then remains constant till the peak stress $\sigma_{\max }=189 \mathrm{MPa}$ (i.e., $\mathrm{B}_{2}-\mathrm{C}$ in Figure 4e).

Table 4 shows the hysteresis loops related parameters of cross-ply $\mathrm{SiC} / \mathrm{SiC}$ composite under $\sigma_{\max }=189$ and $206 \mathrm{MPa}$. When the peak stress increases from $\sigma_{\max }=189$ to $206 \mathrm{MPa}$, the interface debonding ratio increases from $\eta=0.214$ to 0.35 ; the unloading transition stress decreases from $\sigma_{\text {tr_unlooading }}=52$ to $34 \mathrm{MPa}$; the unloading ITM increases from ITM $=8.67$ to $10.32 \mathrm{TPa}^{-1}$; the unloading peak ICSR increases from 0.09 to 0.137 ; the reloading transition stress increases from $\sigma_{\text {tr_relooading }}=137$ to $172 \mathrm{MPa}$; the reloading ITM increases from ITM $=7.69$ to $9.68 \mathrm{TPa}^{-1}$; and the reloading peak INSR increases from 0.214 to 0.35 .

Table 4. Hysteresis loops parameters of cross-ply $\mathrm{SiC} / \mathrm{SiC}$ composite considering closure of matrix fragmentation.

\begin{tabular}{ccc}
\hline Items & $\sigma_{\max }=\mathbf{1 8 9} \mathbf{M P a}$ & $\sigma_{\max }=\mathbf{2 0 6} \mathbf{M P a}$ \\
\hline$\eta$ & 0.214 & 0.35 \\
\hline$\sigma_{\text {tr_unloading }} /(\mathrm{MPa})$ & 52 & 34 \\
\hline$\sigma_{\text {tr_reloading }} /(\mathrm{MPa})$ & 137 & 172 \\
\hline Unloading Peak ITM/(TPa $\left.{ }^{-1}\right)$ & 8.67 & 10.32 \\
\hline Reloading Peak ITM/(TPa $\left.{ }^{-1}\right)$ & 7.69 & 9.68 \\
\hline Unloading Peak ICSR & 0.09 & 0.137 \\
\hline Reloading Peak INSR & 0.214 & 0.35 \\
\hline
\end{tabular}

\subsection{Prediction of Tensile and Fatigue Hysteresis Loops of 2D Plain-Woven SiC/SiC Composite}

Smith [35] performed experimental study on the tensile and cyclic loading/unloading hysteresis behavior of $2 \mathrm{D}$ plain-woven $\mathrm{SiC} / \mathrm{SiC}$ composite at room temperature. The 
composite was fabricated using the CVI+MI method at temperature near $1400{ }^{\circ} \mathrm{C}$. The Sylramic ${ }^{\mathrm{TM}}$ fibers were coated with a Boron Nitride (BN) interphase.

Figure 5 shows experimental and predicted tensile stress-strain curves. The composite exhibited obvious nonlinear behavior and fractured at approximately $\sigma_{\mathrm{UTS}}=430 \mathrm{MPa}$ with the failure strain of $\varepsilon_{\mathrm{f}}=0.36 \%$.

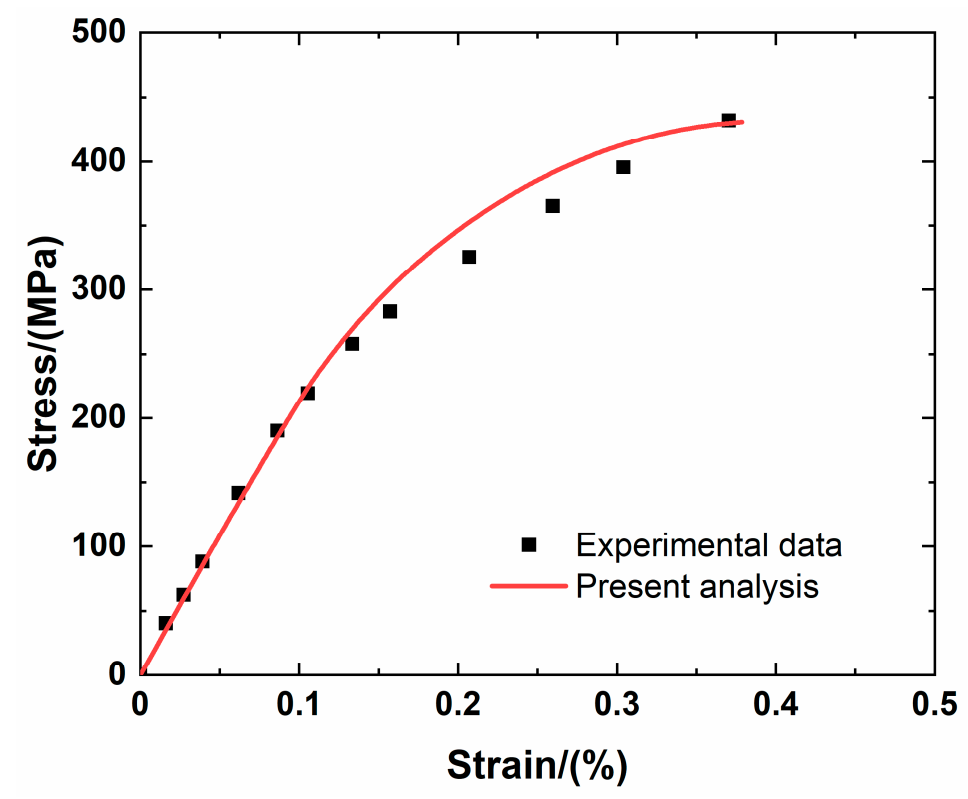

Figure 5. Experimental and predicted tensile curves of $2 \mathrm{D}$ plain-woven $\mathrm{SiC} / \mathrm{SiC}$ composite.

Figure 6 show the experimental and predicted stress-strain hysteresis loops, ITM, and ICSR/INSR versus stress curves under $\sigma_{\max }=360 \mathrm{MPa}$. Theoretical predicted hysteresis loops considering closure of matrix fragmentation agreed with experimental data, as shown in Figure 6a.

(a) Under $\sigma_{\max }=360 \mathrm{MPa}$, when the closure of matrix fragmentation is not considered, the unloading ITM increases with unloading stress due to internal damage of interface debonding and counter sliding, i.e., from ITM $=4.59 \mathrm{TPa}^{-1}$ at the peak stress $\sigma_{\max }=$ $360 \mathrm{MPa}$ to ITM $=5.63 \mathrm{TPa}^{-1}$ at the unloading transition stress $\sigma_{\text {tr_unloading }}=91 \mathrm{MPa}$ (i.e., $\mathrm{A}-\mathrm{B}_{1}$ in Figure $6 \mathrm{~b}$ ), and then increases to ITM $=6.04 \mathrm{TPa}^{-1}$ at the valley stress $\sigma_{\min }=$ zero $\mathrm{MPa}$ (i.e., $\mathrm{B}_{1}-\mathrm{C}_{1}$ in Figure $6 \mathrm{~b}$ ); the reloading ITM increases with reloading stress due to internal damage of interface debonding and new sliding, i.e., from ITM $=4.59 \mathrm{TPa}^{-1}$ at the valley stress $\sigma_{\text {min }}=$ zero MPa to ITM $=5.63 \mathrm{TPa}^{-1}$ at the reloading transition stress $\sigma_{\text {tr_reloading }}=269 \mathrm{MPa}$ (i.e., A-B $\mathrm{B}_{1}$ in Figure 6c), and increases to ITM $=6.04 \mathrm{TPa}^{-1}$ at the tensile peak stress $\sigma_{\max }=360 \mathrm{MPa}$ (i.e., $\mathrm{B}_{1}-\mathrm{C}_{1}$ in Figure $6 \mathrm{c}$ ); the unloading ICSR increases with unloading stress due to the increase of the interface counter slip length, i.e., from ICSR $=$ zero at the tensile peak stress $\sigma_{\max }=360 \mathrm{MPa}$ to ICSR $=0.15$ at the unloading transition stress $\sigma_{\text {tr_unloading }}=91 \mathrm{MPa}$ (i.e., $\mathrm{A}-\mathrm{B}_{1}$ in Figure $6 \mathrm{~d}$ ), and remains constant till the valley stress $\sigma_{\min }=$ zero $\mathrm{MPa}$ (i.e., $\mathrm{B}_{1}-\mathrm{C}_{1}$ in Figure $6 \mathrm{~d}$ ); and the reloading INSR increases with reloading stress due to the increase of the interface new slip length, i.e., from INSR = zero at the valley stress $\sigma_{\min }=$ zero MPa to INSR $=0.15$ at the reloading transition stress $\sigma_{\text {tr_reloading }}=269 \mathrm{MPa}$ (i.e., $\mathrm{A}-\mathrm{B}_{1}$ in Figure $6 \mathrm{e}$ ), and then remains constant till the tensile peak stress $\sigma_{\max }=$ $360 \mathrm{MPa}$ (i.e., $\mathrm{B}_{1}-\mathrm{C}$ in Figure 6e).

(b) When the closure of matrix fragmentation is considered, the unloading ITM increases with unloading stress due to internal damage of interface debonding and counter sliding, i.e., from ITM $=4.63 \mathrm{TPa}^{-1}$ at the tensile peak stress $\sigma_{\max }=360 \mathrm{MPa}$ to ITM $=$ $7.08 \mathrm{TPa}^{-1}$ at the unloading stress $\sigma_{\text {unloading }}=54 \mathrm{MPa}$ (i.e., A-B $\mathrm{B}_{2}$ in Figure $6 \mathrm{~b}$ ), and then decreases to ITM $=6.87 \mathrm{TPa}^{-1}$ at the valley stress $\sigma_{\min }=$ zero $\mathrm{MPa}$ (i.e., $\mathrm{B}_{2}-\mathrm{C}_{2}$ in 
Figure $6 b)$; the reloading ITM increases with reloading stress due to internal damage of interface debonding and new sliding, i.e., from ITM $=4.58 \mathrm{TPa}^{-1}$ at the valley stress $\sigma_{\text {min }}=$ zero $\mathrm{MPa}$ to ITM $=6.67 \mathrm{TPa}^{-1}$ at the reloading stress $\sigma_{\text {reloading }}=269 \mathrm{MPa}$ (i.e., $\mathrm{A}-\mathrm{B}_{2}$ in Figure $6 \mathrm{c}$ ), and increases slowly to ITM $=6.88 \mathrm{TPa}^{-1}$ at the tensile peak stress $\sigma_{\max }=360 \mathrm{MPa}$ (i.e., $\mathrm{B}_{2}-\mathrm{C}_{2}$ in Figure $6 \mathrm{c}$ ); the unloading ICSR increases with unloading stress due to the increase of the interface counter slip length, i.e., from ICSR $=$ zero at the peak stress $\sigma_{\max }=360 \mathrm{MPa}$ to ICSR $=0.082$ at the unloading stress $\sigma_{\text {unloading }}=169 \mathrm{MPa}$ (i.e., $\mathrm{A}-\mathrm{B}_{2}$ in Figure $6 \mathrm{~d}$ ), and decreases to ICSR = zero the valley stress $\sigma_{\min }=$ zero $\mathrm{MPa}$ (i.e., $\mathrm{B}_{2}-\mathrm{C}_{2}$ in Figure $6 \mathrm{~d}$ ); and the reloading INSR increases with reloading stress due to the increase of the interface new slip length, i.e., from INSR $=$ zero at the valley stress $\sigma_{\min }=$ zero $\mathrm{MPa}$ to $\mathrm{INSR}=0.15$ at the reloading stress $\sigma_{\text {reloading }}=307 \mathrm{MPa}$ (i.e., $\mathrm{A}-\mathrm{B}_{2}$ in Figure 6e), and then remains constant till the peak stress $\sigma_{\max }=360 \mathrm{MPa}$ (i.e., $\mathrm{B}_{2}-\mathrm{C}$ in Figure 6e).
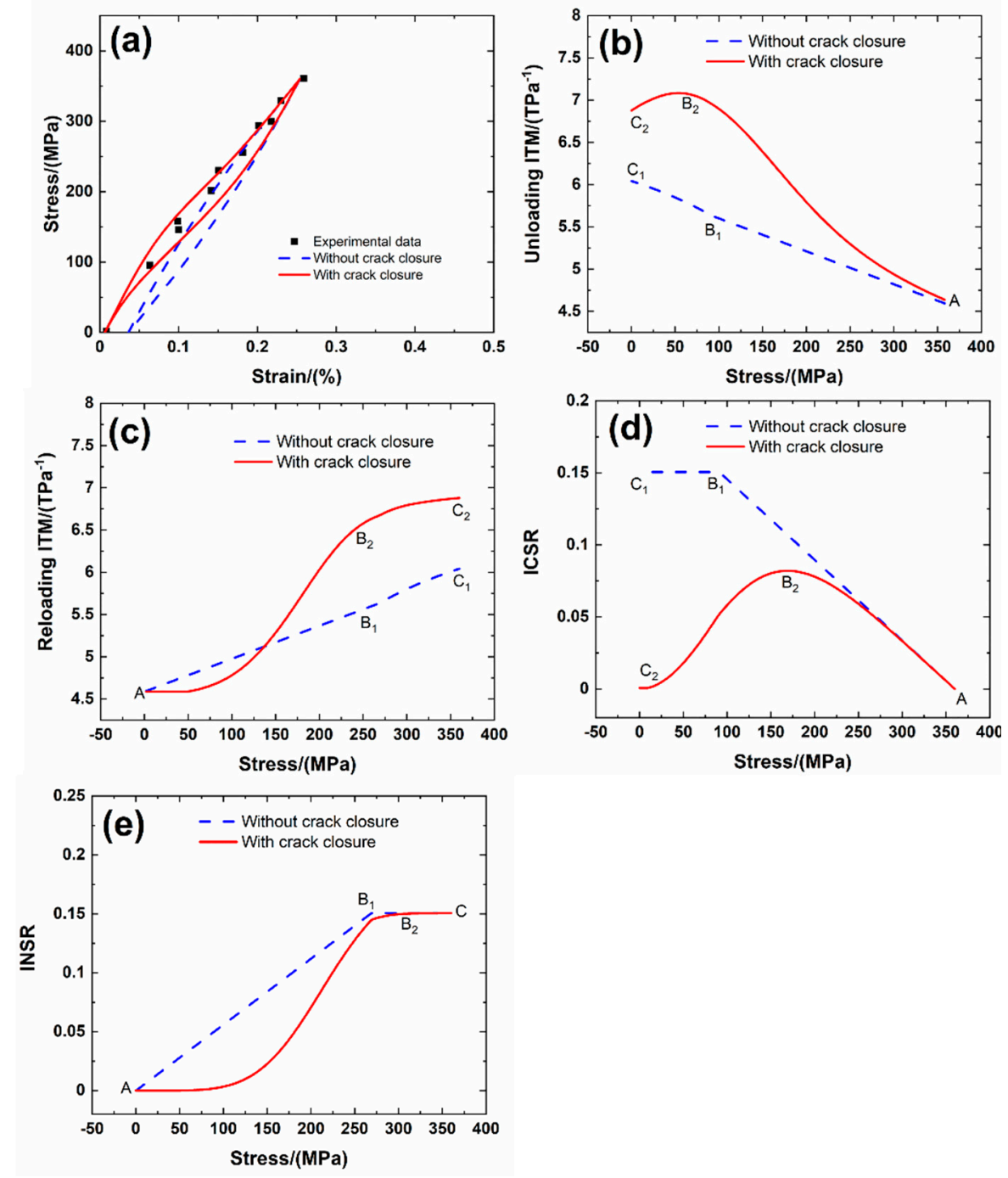

Figure 6. (a) Experimental and predicted hysteresis loops; (b) unloading ITM; (c) reloading ITM; (d) unloading ICSR; and (e) reloading INSR of 2D plain-woven $\mathrm{SiC} / \mathrm{SiC}$ composite under $\sigma_{\max }=$ $360 \mathrm{MPa}$.

Table 5 shows the hysteresis loops parameters under $\sigma_{\max }=312,360$, and $410 \mathrm{MPa}$. When the tensile peak stress increases from $\sigma_{\max }=312$ to $410 \mathrm{MPa}$, the interface debonding ratio increases from $\eta=0.084$ to 0.23 ; the unloading transition stress decreases from $\sigma_{\text {tr_unlooading }}=138$ to $41 \mathrm{MPa}$; the unloading ITM increases from ITM $=6.32$ to $8.01 \mathrm{TPa}^{-1}$; 
the unloading peak ICSR increases from 0.054 to 0.098 ; the reloading transition stress increases from $\sigma_{\text {tr_relooading }}=174$ to $369 \mathrm{MPa}$; the reloading ITM increases from ITM $=6.12$ to $7.73 \mathrm{TPa}^{-1}$; and the reloading peak INSR increases from 0.084 to 0.23 .

Table 5. Hysteresis loops parameters of 2D plain-woven $\mathrm{SiC} / \mathrm{SiC}$ composite considering closure of matrix fragmentation.

\begin{tabular}{cccc}
\hline Items & $\sigma_{\max }=312 \mathbf{M P a}$ & $\sigma_{\max }=360 \mathbf{M P a}$ & $\sigma_{\max }=410 \mathbf{M P a}$ \\
\hline$\eta$ & 0.084 & 0.15 & 0.23 \\
\hline$\sigma_{\text {tr_unloading }} /(\mathrm{MPa})$ & 138 & 91 & 41 \\
\hline$\sigma_{\text {tr_reloading }} /(\mathrm{MPa})$ & 174 & 269 & 369 \\
\hline $\left.\begin{array}{c}\text { Unloading Peak } \\
\text { ITM/(TPa }\end{array}{ }^{-1}\right)$ & 6.32 & 7.08 & 8.01 \\
\hline $\left.\begin{array}{c}\text { Reloading Peak } \\
\text { ITM/(TPa }\end{array}{ }^{-1}\right)$ & 6.12 & 6.87 & 7.73 \\
\hline Unloading Peak ICSR & 0.054 & 0.08 & 0.098 \\
\hline Reloading Peak INSR & 0.084 & 0.15 & 0.23 \\
\hline
\end{tabular}

\subsection{Comparative Analysis}

Under tensile and fatigue loading, composite's internal damage evolution depends on the fiber's preform and volume fraction. For minicomposite, unidirectional, cross-ply and 2D plain-woven $\mathrm{SiC} / \mathrm{SiC}$ composites with different fiber volume fraction, it can be found that the composite's unloading and reloading peak ITMs decrease with increasing fiber's volume faction.

- For mini-SiC/SiC composite with the fiber' volume of $V_{\mathrm{f}}=0.43$, when the tensile peak stress increases from $\sigma_{\max }=890$ to $1078 \mathrm{MPa}$, the unloading peak ITM increases from ITM $=3.58$ to $5.18 \mathrm{TPa}^{-1}$; the reloading ITM increases from ITM $=3.486$ to $4.87 \mathrm{TPa}^{-1}$. - For cross-ply $\mathrm{SiC} / \mathrm{SiC}$ composite with fiber's volume of $V_{\mathrm{f}}=0.25$, when the peak stress increases from $\sigma_{\max }=189$ to $206 \mathrm{MPa}$, the unloading ITM increases from ITM = 8.67 to $10.32 \mathrm{TPa}^{-1}$; the reloading ITM increases from ITM $=7.69$ to $9.68 \mathrm{TPa}^{-1}$.

The composite's interface debonding and slip parameters, i.e., the interface debonding ratio $(\eta)$, the interface counter slip ratio (ICSR) and interface new slip ratio (INSR) decrease with increasing fiber's volume fraction.

- For mini-SiC $/ \mathrm{SiC}$ composite with the fiber' volume of $V_{\mathrm{f}}=0.43$, when the tensile peak stress increases from $\sigma_{\max }=890$ to $1078 \mathrm{MPa}$, the interface debonding ratio increases from $\eta=0.075$ to 0.38 ; the unloading peak ICSR increases from 0.07 to 0.17 ; and the reloading peak INSR increases from 0.075 to 0.38 .

- For unidirectional $\mathrm{SiC} / \mathrm{SiC}$ composite with fiber's volume of $V_{\mathrm{f}}=0.25$, when the peak stress increases from $\sigma_{\max }=415$ to $449 \mathrm{MPa}$, the interface debonding ratio increases from $\eta=0.14$ to 0.295 ; the unloading peak ICSR increases from 0.11 to 0.1888 ; and the reloading peak INSR increases from 0.14 to 0.295 .

\section{Summary and Conclusions}

In this paper, micromechanical constitutive models were developed to analyze the effects of matrix fragmentation and closure on tensile and fatigue behavior of fiber-reinforced CMCs. Relationships between composite's tensile and fatigue response, matrix fragmentation and closure and related interface debonding and fiber's failure were established. Experimental matrix fragmentation density, tensile curves, and fatigue hysteresis loops of mini, unidirectional, cross-ply, and 2D plain-woven $\mathrm{SiC} / \mathrm{SiC}$ composites are predicted.

(1) The Matrix fragmentation density changes with increasing or decreasing tensile stress and affects the tensile nonlinear strain and the interface debonding ratio. 
(2) The closure of matrix fragmentation affects the fatigue hysteresis loops. Upon unloading, the inverse tangent modulus increases to the peak value, and then decreases with unloading stress, and the interface counter slip ratio increases to the peak value, and then decreases to zero with unloading stress; upon reloading, the inverse tangent modulus increases with reloading stress, and the interface new slip ratio increases slowly during initial stage of reloading, then increases to the peak value, and remains constant till peak stress.

(3) Theoretical predicted matrix fragmentation density, tensile nonlinear curves, and the fatigue hysteresis loops agreed with experimental data.

There is inherent variation across samples tested in CMCs, however, the paper focused on the micromechanical constitutive models for tensile and fatigue behavior of CMCs without considering the inherent variation for different tested samples. The author will consider the inherent variation for different samples tested in CMCs in the further study.

Funding: This research was funded by the Fundamental Research Funds for the Central Universities of China [Grant No. NS2019038].

Acknowledgments: The work reported here is supported by the Fundamental Research Funds for the Central Universities of China (Grant No. NS2019038). The authors also wish to thank two anonymous reviewers and editors for their helpful comments on an earlier version of the paper.

Conflicts of Interest: The author declares that he has no known competing financial interests or personal relationships that could have appeared to influence the work reported in this paper.

\section{References}

1. Naslain, R. Design, preparation and properties of non-oxide CMCs for application in engines and nuclear reactors: An overview. Compos. Sci. Technol. 2004, 64, 155-170. [CrossRef]

2. Li, L.B. Durability of Ceramic Matrix Composites; Woodhead Publishing: Oxford, UK, 2020. [CrossRef]

3. Li, L.B. High Temperature Mechanical Behavior of Ceramic-Matrix Composites; Wiley-VCH: Weinheim, Germany, 2021.

4. Li, L.B. Damage and Fracture of Ceramic-Matrix Composites under Stochastic Loading; Springer Nature: Singapore, 2021. [CrossRef]

5. Li, L.B. Damage, Fracture and Fatigue of Ceramic-Matrix Composite; Springer Nature: Singapore, 2018. [CrossRef]

6. Li, L.B. Thermomechanical Fatigue of Ceramic-Matrix Composites; Wiley-VCH: Weinheim, Germany, 2019.

7. Li, L.B. Interfaces of Ceramic-Matrix Composites. Design, Characterization and Damage Effects; Wiley-VCH: Weinheim, Germany, 2020.

8. Li, L.B. Nonlinear Behavior of Ceramic-Matrix Composites; Woodhead Publishing: Oxford, UK, 2021.

9. Ikarashi, Y.; Ogasawara, T.; Aoki, T. Micromechanical model of time-dependent damage and deformation behavior for an orthogonal 3D-woven $\mathrm{SiC} / \mathrm{SiC}$ composite at elevated temperature in vacuum. J. Eur. Ceram. Soc. 2020, 40, 3887-3896. [CrossRef]

10. Mu, Y.; Zhou, W.; Luo, F.; Zhu, D. Effects of BN/SiC dual-layer interphase on mechanical and dielectric properties of SiCf/SiC composites. Ceram. Int. 2014, 40, 3411-3418. [CrossRef]

11. Sevener, K.M.; Tracy, J.M.; Chen, Z.; Kiser, J.D.; Daly, S. Crack opening behavior in ceramic matrix composites. J. Am. Ceram. Soc. 2017, 100, 4734-4747. [CrossRef]

12. Li, L. A micromechanical crack opening displacement model for fiber-reinforced ceramic-matrix composites considering matrix fragmentation. Theor. Appl. Fract. Mech. 2021, 112, 102875. [CrossRef]

13. Chen, Y.; Gelebart, L.; Chateau, C.; Bornert, M.; King, A.; Sauder, C.; Aimedieu, P. Crack initiation and propagation in braided $\mathrm{SiC} / \mathrm{SiC}$ composite tubes: Effect of braiding angle. J. Eur. Ceram. Soc. 2020, 40, 4403-4418. [CrossRef]

14. Longbiao, L. Synergistic effects of fiber debonding and fracture on matrix cracking in fiber-reinforced ceramic-matrix composites. Mater. Sci. Eng. A 2017, 682, 482-490. [CrossRef]

15. Morscher, G.N.; Baker, C.A.; Smith, C.E. Electrical Resistance of SiC Fiber Reinforced SiC/Si Matrix Composites at Room Temperature during Tensile Testing. Int. J. Appl. Ceram. Technol. 2014, 11, 263-272. [CrossRef]

16. Goulmy, J.P.; Camus, G.; Rebillat, F. Monitoring damage evolution of ceramic matrix composites during tensile tests using electrical resistivity: Crack density-based electromechanical model. J. Eur. Ceram. Soc. 2021, 41, 121-129. [CrossRef]

17. Li, L. Modeling matrix fracture in fiber-reinforced ceramic-matrix composites with different fiber preforms. Text. Res. J. 2020, 90, 909-924. [CrossRef]

18. Curtin, W.; Ahn, B.; Takeda, N. Modeling brittle and tough stress-strain behavior in unidirectional ceramic matrix composites. Acta Mater. 1998, 46, 3409-3420. [CrossRef]

19. Evans, A.; Zok, F.; McMeeking, R.; Evans, A.; Zok, F.; McMeeking, R. Fatigue of ceramic matrix composites. Acta Met. Mater. 1995, 43, 859-875. [CrossRef]

20. Reynaud, P. Cyclic fatigue of ceramic-matrix composites at ambient and elevated temperatures. Compos. Sci. Technol. 1996, 56, 809-814. [CrossRef] 
21. Staehler, J.M.; Mall, S.; Zawada, L.P. Frequency dependence of high-cycle fatigue behavior of CVI C/SiC at room temperature. Compos. Sci. Technol. 2003, 63, 2121-2131. [CrossRef]

22. Ruggles-Wrenn, M.; Christensen, D.; Chamberlain, A.; Lane, J.; Cook, T. Effect of frequency and environment on fatigue behavior of a CVI SiC/SiC ceramic matrix composite at $1200^{\circ}$ C. Compos. Sci. Technol. 2011, 71, 190-196. [CrossRef]

23. Li, L. Fatigue hysteresis behavior of cross-ply C/SiC ceramic matrix composites at room and elevated temperatures. Mater. Sci. Eng. A 2013, 586, 160-170. [CrossRef]

24. Longbiao, L. Fatigue hysteresis behavior in fiber-reinforced ceramic-matrix composites at room and elevated temperatures. Ceram. Int. 2017, 43, 2614-2624. [CrossRef]

25. Longbiao, L. Hysteresis loops of carbon fiber-reinforced ceramic-matrix composites with different fiber preforms. Ceram. Int. 2016, 42, 16535-16551. [CrossRef]

26. Ahn, B. Strain and hysteresis by stochastic matrix cracking in ceramic matrix composites. J. Mech. Phys. Solids 1997, 45, 177-209. [CrossRef]

27. Liu, Y.; Li, L.; Zhang, Z.; Wang, Y. Micromechanical modeling cyclic loading/unloading hysteresis loops of 3D needle-punched $\mathrm{C} / \mathrm{SiC}$ ceramic-matrix composites. Compos. Interfaces 2021, 1-24. [CrossRef]

28. Li, L. Micromechanical modeling of cyclic non-closure hysteresis loops of fiber-reinforced ceramic-matrix composites considering variable matrix fragmentation density. Mater. Sci. Eng. A 2021, 805, 140795. [CrossRef]

29. Curtin, W. Multiple matrix cracking in brittle matrix composites. Acta Met. Mater. 1993, 41, 1369-1377. [CrossRef]

30. Gao, Y.-C.; Mai, Y.-W.; Cotterell, B. Fracture of fiber-reinforced materials. J Appl. Math. Phys. 1988, 39, 550-572. [CrossRef]

31. Curtin, W.A. Theory of Mechanical Properties of Ceramic-Matrix Composites. J. Am. Ceram. Soc. 1991, 74, 2837-2845. [CrossRef]

32. Sauder, C.; Brusson, A.; Lamon, J. Influence of Interface Characteristics on the Mechanical Properties of Hi-Nicalon type-S or Tyranno-SA3 Fiber-Reinforced SiC/SiC Minicomposites. Int. J. Appl. Ceram. Technol. 2010, 7, 291-303. [CrossRef]

33. Domergue, J.-M.; Vagaggini, E.; Evans, A.G. Relationships between Hysteresis Measurements and the Constituent Properties of Ceramic Matrix Composites: II, Experimental Studies on Unidirectional Materials. J. Am. Ceram. Soc. 1995, 78, $2721-2731$. [CrossRef]

34. Gordon, N. Material Health Monitoring of $\mathrm{SiC} / \mathrm{SiC}$ Laminated Ceramic Matrix Composites with Acoustic Emission and Electrical Resistance. Master's Thesis, University of Akron, Akron, OH, USA, 2014.

35. Smith, C.E. Electrical Resistance Changes of Melt Infiltrated SiC/SiC Subjected to Long-Term Tensile Loading at Elevated Temperature. Ph.D. Thesis, University of Akron, Akron, OH, USA, 2016. 